\title{
Agricultura y política agrícola en Canadá en los noventa
}

\author{
DOI: 10.32870/mycp.v6i19.199
}

Melba E. Falck*

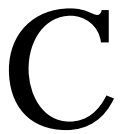

anadá es un actor destacado en los mercados mundiales de alimentos; durante los noventa su importancia ha ido en aumento. En ese período dicho país ha aplicado determinantes reformas en la política agrícola tendentes a liberalizar el sector, eliminando subsidios y disminuyendo la protección de frontera, pero al mismo tiempo aplicando programas para dar seguridad al ingreso de los productores y compensar la pérdida de los apoyos tradicionales.

En esta contribución presento un esbozo de la situación actual de la agricultura canadiense y de las principales medidas de política agrícola de los noventa.

Canadá posee un territorio de 9.2 millones de kilómetros cuadrados (más de cuatro veces el correspondiente a México) y cuenta con 31 millones de habitantes (menos de la tercera parte de la población mexicana). Con esos recursos, la economía canadiense ocupa el cuarto lugar entre las veintiún economías que forman parte del Mecanismo de Cooperación de Asia Pacífico (APEC, por sus siglas en inglés). Los canadienses poseen un elevado nivel de vida, con un ingreso per cápita medido en dólares internacionales (que muestra el poder de compra) de 27170 , tres veces superior al de los mexicanos.

Canadá es un país con un alto grado de apertura externa. Como porcentaje del Producto Interno Bruto (PIB), las exportaciones e importaciones representan más de cuarenta por ciento cada una de la producción nacional, con un nivel de 276 y 245 mil millones de dólares respectivamente en el año $2000 .{ }^{1} \mathrm{El}$ crecimiento del sector externo canadiense se ha visto impulsado por la firma del Tratado de Libre Comercio de América del Norte (TLCAN).

* Investigadora y jefa del Departamento de Estudios del Pacífico, de la Universidad de Guadalajara.

ORCID http://orcid.org/0000-0003-4926-0594
El comercio total entre Estados Unidos y Canadá alcanzó los 588 mil millones de dólares en 2000 y con México se duplicó entre 1994 a 2000 a 14 mil millones de dólares. Canadá exporta a sus socios del TLCAN alrededor de 87 por ciento de sus ventas externas, sobre todo a Estados Unidos. ${ }^{2}$

Canadá es el tercer exportador mundial de productos agroalimentarios. En el APEC, es también el tercer exportador de alimentos más importante (después de Estados Unidos y Australia), con un nivel promedio en el período 1994 a 2000 de 14 mil millones de dólares, más del doble de las exportaciones agroalimentarias de México. Canadá es también un destacado importador de alimentos, el segundo en el APEC después de Estados Unidos, con un nivel promedio de importaciones de $10 \mathrm{mil} \mathrm{mi-}$ llones de dólares en el período referido. Canadá es así un exportador neto de alimentos. $^{3}$

\section{Importancia del sector agrícola}

Como la mayoría de los países desarrollados, las actividades agrícolas han ido perdiendo participación relativa en la economía canadiense, para dar paso a la industria y en especial a los servicios. Actualmente, el sector agrícola de Canadá representa 2.2 por ciento del PIB y emplea a 3.4 por ciento de la fuerza de trabajo. Sin embargo, estas cifras no reflejan la importancia real de las actividades agroindustriales para la economía canadiense. Así, si se toma en cuenta la agroindustria, los indicadores anteriores se elevan a 4 y 5 por ciento respectivamente. Más aún, si se consideran ciertos servicios a la agricultura, este sector es la tercera fuente de empleo en Canadá y una de sus ramas de producción más sobresalientes. En el total de exportaciones, las agroindustriales representan 5.3 por ciento y las importaciones, 4.5 por ciento. ${ }^{4}$ 
El principal cultivo de Canadá es el trigo, que ocupa alrededor 40 por ciento de la superficie cultivada. Es el tercer mayor productor de trigo y el segundo exportador. Sin embargo, con la eliminación de los subsidios al transporte de cereales en la región occidental en 1995, ha habido un impulso a la producción de oleaginosas (16 por ciento de la superficie cultivada): legumbres, papas y maíz para consumo humano. En las actividades pecuarias se han expandido las de ganado bovino y porcino. El occidente de Canadá domina en la producción de carne, con las Provincias de la Pradera, representando 84 por ciento del total. Las Provincias del este contribuyen con 77 por ciento de la producción láctea, especialmente Québec y Ontario. Las zonas de mayor producción de ganado porcino son también las del este; Québec y Ontario, las que tienen mayores inventarios. Pero el mayor crecimiento del hato de ganado porcino se ha dado en el oeste, específicamente en las provincias de Manitoba y Alberta. Esto tiene que ver con la eliminación de los subsidios al transporte de granos, lo que redujo los precios de los granos forrajeros. ${ }^{5}$

Otro indicador de la relevancia del sector agrícola es la proporción exportada del total de la producción agroalimentaria, que constituye actualmente alrededor de una quinta parte de la misma. Las exportaciones agroalimentarias en el período 1990-2001 prácticamente se duplicaron, al pasar de 9 a 17 mil millones de dólares; por lo tanto, para Canadá el acceso a los mercados mundiales alimentarios es muy importante. Las importaciones agroalimentarias, por su parte, representan 15 por ciento de las ventas internas. Éstas pasaron de 7 a 12 mil millones de dólares en el período mencionado (cuadro 1 ).

Cuadro 1 Canadá: exportaciones e importaciones agrícolas (millones de dólares)

\begin{tabular}{rcccc}
\hline Año & Exportaciones & $\begin{array}{c}\text { Tasa de } \\
\text { crecimiento }\end{array}$ & Importaciones & $\begin{array}{c}\text { Tasa de } \\
\text { crecimiento }\end{array}$ \\
\hline 1990 & $9,181,264$ & & $7,100,642$ & \\
1991 & $9,619,024$ & 4.8 & $7,346,121$ & 3.5 \\
1992 & $10,925,605$ & 13.6 & $7,585,117$ & 3.3 \\
1993 & $10,351,027$ & -5.3 & $7,983,817$ & 5.3 \\
1994 & $11,238,972$ & 8.6 & $8,606,709$ & 7.8 \\
1995 & $12,788,891$ & 13.8 & $9,079,771$ & 5.5 \\
1996 & $14,702,485$ & 15.0 & $9,522,567$ & 4.9 \\
1997 & $15,191,571$ & 3.3 & $10,515,626$ & 10.4 \\
1998 & $15,393,712$ & 1.3 & $10,848,696$ & 3.2 \\
1999 & $14,683,034$ & -4.6 & $10,847,979$ & 0.0 \\
2000 & $15,684,949$ & 6.8 & $11,441,510$ & 5.5 \\
2001 & $17,270,521$ & 10.1 & $12,038,450$ & 5.2 \\
& & & & \\
Promedio & & & & \\
$1990-2001$ & $13,085,921$ & 6.1 & $9,409,750$ & 4.9 \\
1994-2001 & $14,619,267$ & 6.8 & $10,362,664$ & 5.3 \\
\hline
\end{tabular}

Fuente: FAO, Crops and Livestock Primary and Processed.

http://apps.fao.org/ 
El principal socio comercial de Canadá en el comercio alimentario es Estados Unidos, a quien destina 61 por ciento de sus exportaciones; Estados Unidos le provee 62 por ciento de sus importaciones. Las principales importaciones de Canadá procedentes de Estados Unidos son frutas y vegetales (31 por ciento), animales y productos animales (19 por ciento) y granos y forrajes (18 por ciento). Canadá es de hecho el principal mercado de Estados Unidos en las exportaciones de frutas y vegetales. En los noventa las importaciones de alimentos procedentes de Canadá aumentaron 11 por ciento promedio anual, mientras que las exportaciones de Estados Unidos a Canadá se incrementaron 6 por ciento anualmente. El comercio agrícola entre los dos países se ha visto incrementado por el TLCAN, los menores apoyos a los precios y mayores ingresos en ambos países. Otros socios agrícolas importantes para Canadá son Japón y la Unión Europea. Granos y carnes rojas son de los principales productos de exportación de $\mathrm{Ca}$ nadá hacia esos mercados. ${ }^{6}$

\section{Autosuficiencia alimentaria}

Considerando los principales grupos de productos alimenticios, Canadá produce excedentes por arriba de sus necesidades de consumo en cereales, oleaginosas y carne; mientras que en vegetales y frutas depende de las importaciones para complementar su consumo. Por productos específicos en cereales sus mayores excedentes los obtiene en la producción de trigo y cebada, aunque es dependiente de las importaciones de arroz para satisfacer su consumo. En oleaginosas, Canadá importa alrededor de un treinta por ciento de sus necesidades de consumo; en el grupo de los vegetales, alrededor de un 40 por ciento y en frutas, el ochenta por ciento. En los últimos dos casos la autosuficiencia alimentaria ha tendido a disminuir paulatinamente desde principios de los noventa (cuadro 2). En el grupo de carnes que incluye la de res, cerdo y aves, la producción excede el consumo, sobre todo en las dos primeras.

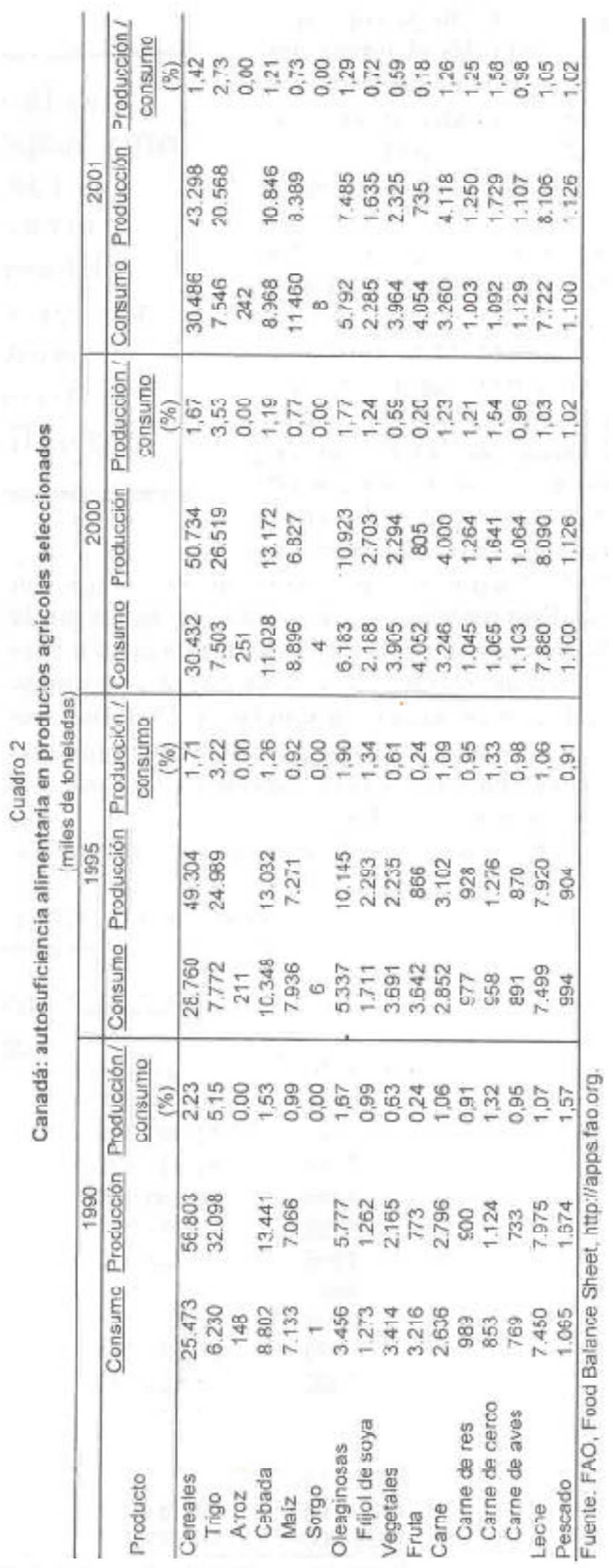




\section{Política agrícola de liberalización}

Comparado al apoyo que otorgan al sector agrícola los países miembros de la Organización para la Cooperación del Desarrollo Económico (OCDE), las transferencias a la agricultura en Canadá son relativamente bajas. En general, los apoyos a la agricultura en este país representan actualmente 18 por ciento del valor de la producción agrícola (PSE), similar al apoyo que otorga México e inferior al de Estados Unidos (cuadro 4). Como porcentaje del PIB, el apoyo total que Canadá destina a sus agricultores representa 0.8 por ciento de ese indicador, inferior al de sus socios en el TLCAN (cuadro 3 ). Por hectárea, los canadienses otorgan a sus agricultores un apoyo de 53 dólares al año, similar al de México y menos de la mitad del que otorgan los estadounidenses. Cada agricultor (equivalente de tiempo completo) recibe 9 mil dólares al año, comparado a los mil que reciben los campesinos mexicanos y a los 21 mil que reciben los productores agrícolas estadounidenses. Tanto México como Canadá otorgan apoyos a sus agricultores por debajo de la media de la OCDE.

En general, de 1986 a 2001, Canadá ha disminuido sustancialmente los apoyos a la agricultura. En ese período las transferencias a los productores agrícolas pasaron de representar 34 por ciento del valor de la producción agrícola al 18 por ciento. Como consecuencia los precios al productor que se situaban 40 por ciento por arriba de los precios internacionales en promedio en 1986-1988, se redujeron de tal forma que actualmente superan a los internacionales sólo en 13 por ciento en promedio. Así, el impuesto implícito al consumo que representan las políticas agrícolas de apoyo al campo y que están representadas por el Estimador de Apoyo al Consumo (CSE), se redujo de 22 a 14 por ciento, beneficiando a los consumidores (cuadro 4).

Los productos con mayores niveles de protección a mediados de los ochenta eran la leche y el trigo, con un PSE por arriba del promedio. Así, los apoyos a la producción de leche constituían casi dos terceras partes del valor de la producción lechera y 45 por ciento del valor de la producción de trigo. Ya en el período de 1999 a 2001, los niveles de protección bajaron considerablemente para el trigo, oleaginosas y carne de aves. La leche continúa siendo el producto más protegido, con un PSE de 54 por ciento, lo que significa que el precio al productor está 115 por ciento por arriba del precio internacional.

Cuadro 3

Apoyos a la agricultura: países seleccionados (1999-2001)

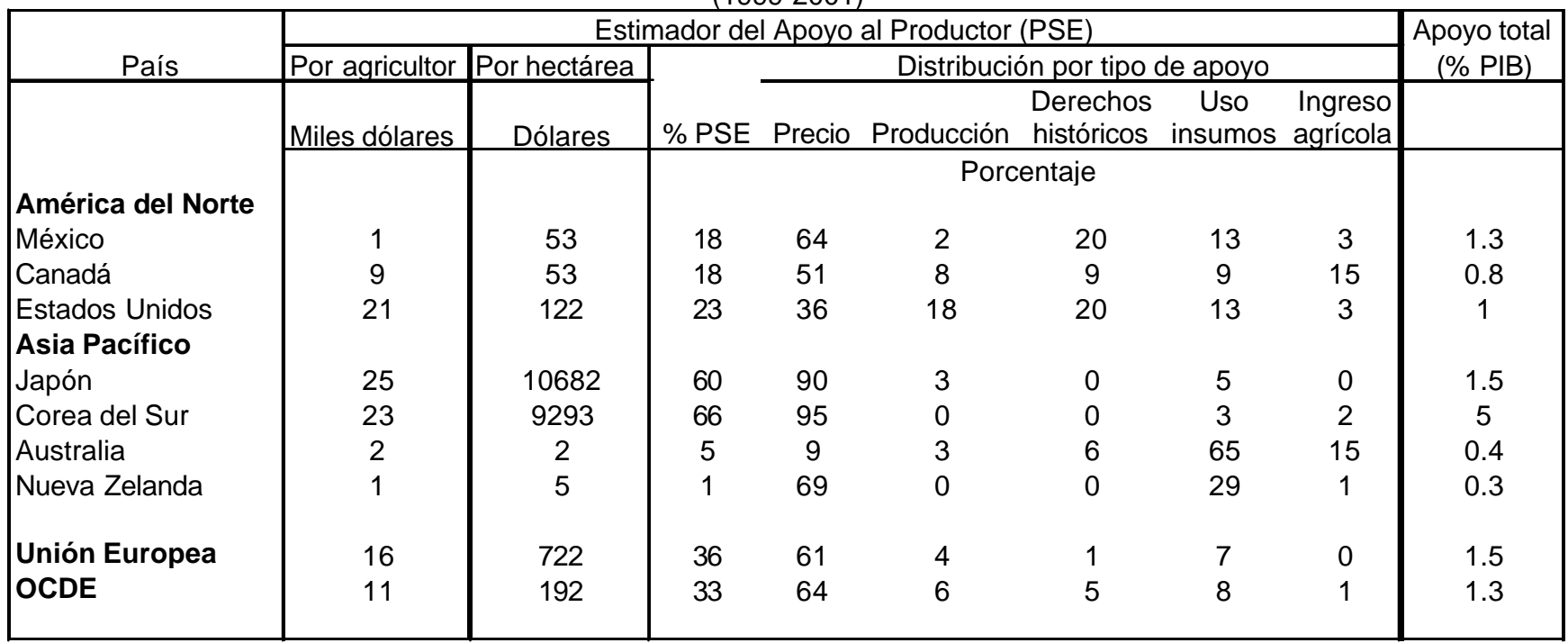

$\%$ PSE, indicador que mide el valor monetario de las transferencias de los consumidores y contribuyentes a los productores agrícolas como porcentaje de los ingresos brutos agrícolas independientes de la estructura productiva del país.

Fuente: OECD, Agricultural Policies in OCDE Countries. Monitoring and Evaluation, 2002. 
Esto se traduce en un impuesto implícito al consumo de 52 por ciento.

Del total de las transferencias a los agricultores, alrededor del 50 por ciento son apoyos al precio. No obstante, Canadá es uno de los países miembros de la OCDE que destina una mayor proporción al apoyo al ingreso de los agricultores. Este tipo de transferencia tiene la ventaja que es la menos distorsionante con respecto a la producción, ya que se otorga independientemente de los cultivos plantados. La tendencia actual es que la mayoría de las transferencias al sector sean de este tipo.

Canadá desde comienzos de los noventa ha ido retirando la ayuda a productos específicos y sustituyéndola por "redes de seguridad de los ingresos", basadas en los ingresos totales de las unidades productoras agrícolas. La subvención a los productos lácteos, que era una ayuda para productos específicos, se suprimió en febrero de 2002. Como se señaló más arriba, el elevado precio de la leche es pagado por los consumidores y no constituye una subvención con cargo al presupuesto. Entre los programas de apoyo al ingreso están la Cuenta de
Estabilización de los Ingresos Netos (NISA, por sus siglas en inglés), los seguros de cosechas, los programas de estabilización de los ingresos a escala provincial y la Ley de programas de comercialización de los productos agrícolas de 1997, según la cual se proporciona a los agricultores anticipos en efectivo en el momento de la cosecha, en algunos casos sin interés. $^{7}$

La NISA ha sido designada para proteger a los agricultores de las fluctuaciones del ingreso agrícola y proveer así estabilidad en el ingreso de largo plazo de los productores. Es esencialmente un instrumento de manejo del riesgo. Tanto los productores como los gobiernos federales y provinciales depositan anualmente dinero en cuentas individuales y del gobierno. Este tipo de apoyo se estableció en 1991 con el fin de sustituir los apoyos específicos a productos. Los agricultores pueden contribuir con 3 por ciento de las ventas netas elegibles y depositarlas en sus cuentas individuales (fondo 1). Las ventas elegibles provienen de las ventas de granos y oleaginosas, exceptuando los productos de oferta administrada como lácteos, aves y huevos. En otra cuenta

Cuadro 4

Canadá: evolución de los apoyos por productos, 1986-1988 a 1999-2001

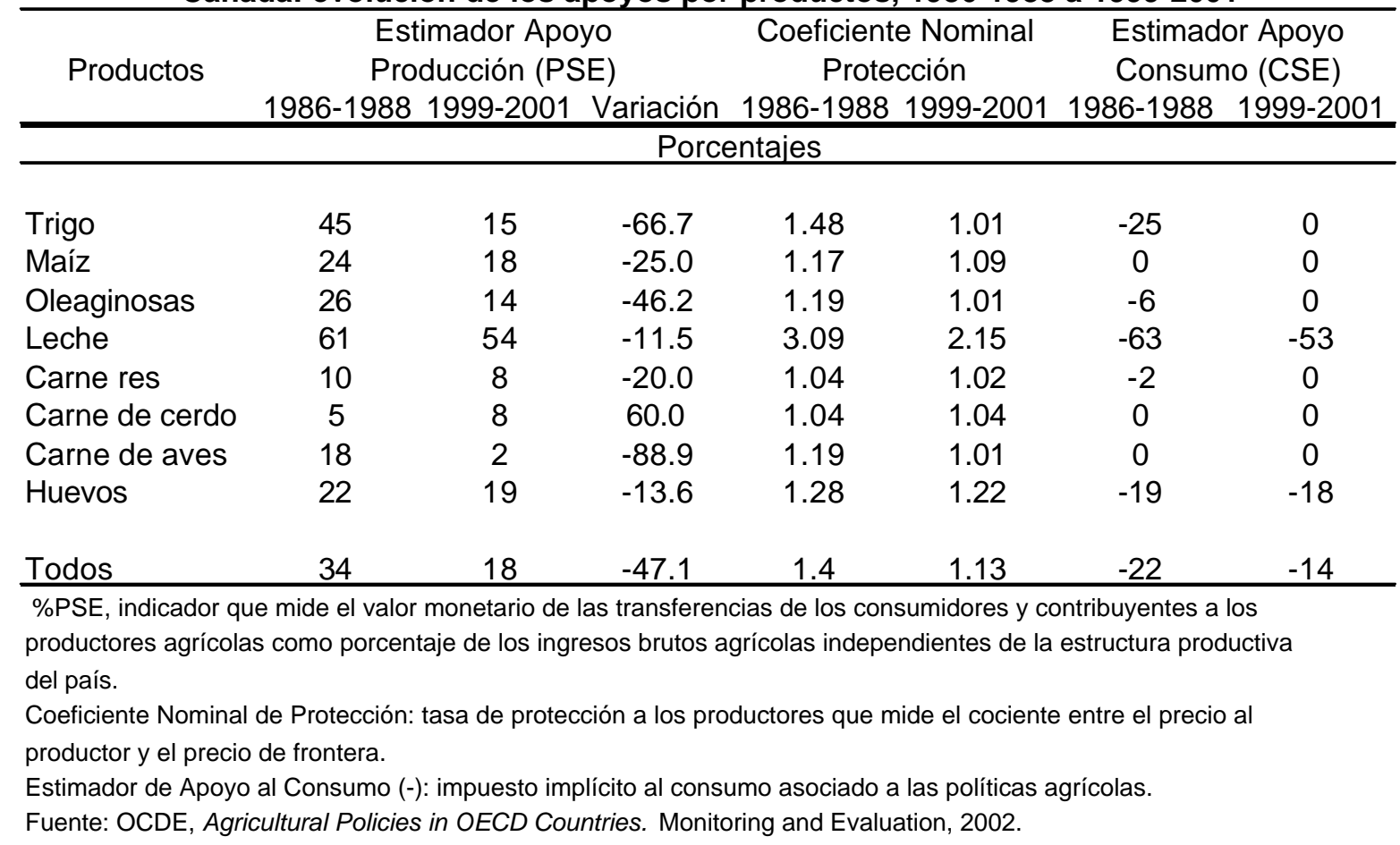


separada (fondo 2), el gobierno federal y provincial depositan 2 y 1 por ciento, respectivamente, de las ventas netas elegibles de los productores. Como incentivo, el gobierno paga una tasa de interés 3 por ciento por arriba del mercado a las contribuciones de los agricultores y los deposita en el fondo 2. Los agricultores pueden retirar fondos si el ingreso agrícola cae por debajo de un cierto nivel o con fines de estabilización de los márgenes de ganancia. Si el margen bruto de ganancia cae por debajo del promedio de los últimos cinco años o si el ingreso cae por debajo de los 10000 dólares canadienses, entonces el agricultor puede retirar fondos. ${ }^{8}$

Los programas de seguro de cultivos son también estrategias de costos compartidos entre productores y gobiernos federales y provinciales.

En 1995 se eliminaron los subsidios de transporte bajo la Ley de Transporte de Granos de Occidente, con el fin de satisfacer los compromisos adquiridos en la Ronda Uruguay del Acuerdo General de Aranceles y Comercio (GATT), y de reducir el déficit gubernamental que ésta implicaba. Esta ley era una de las que más afectaba a la agricultura canadiense. El gobierno subsidiaba completamente los costos del transporte ferroviario, alrededor de 12 dólares estadounidenses por tonelada para movilizar la producción de las provincias a los puertos de exportación. Para compensar a los agricultores por la pérdida del subsidio, el gobierno canadiense estableció dos programas transitorios que concluyeron en 1997 y bajo los cuales se otorgaban pagos por única vez a los productores de granos y oleaginosas. No obstante, el gobierno continúa fijando los cargos por transporte.

Los productos sujetos a regulación de la oferta son básicamente lácteos, huevos, pavos, pollos y sus productos; en menor grado, carne de bovino, margarina, trigo y cebada. Éstos representan alrededor de una quinta parte del total de los ingresos agrícolas. El control de la oferta se realiza mediante las restricciones a las importaciones, las cuales se basan sobre todo en la aplicación de aranceles muy elevados por arriba de las cuotas de importación.
En 2002 los aranceles aplicados a los productos lácteos fuera de cuota oscilaban entre 200 y 300 por ciento. En el caso del trigo, entre 49 y 77 por ciento. Sin embargo, aquellos países con los que Canadá tiene acuerdos de libre comercio, como Chile, México y Estados Unidos, no enfrentan ese tipo de restricciones. El volumen establecido dentro de las cuotas de conformidad con el Acuerdo sobre la Agricultura de la Organización Mundial del Comercio es por lo general bajo. ${ }^{9}$

La regulación de la oferta de productos lácteos, huevos y pollos se hace por medio de las juntas federales y provinciales de comercialización y por las asociaciones de productores. Las dos empresas comerciales del Estado más importantes son la Junta Canadiense del Trigo y la Comisión de Productos Lácteos de Canadá. La primera es la mayor empresa del estado, por el volumen de ventas, y agrupa a más de 100 mil productores de trigo y cebada del occidente de Canadá. Los productores deben vender su producción a través de la Junta.

En el caso de los productos lácteos, el gobierno federal regula el comercio entre provincias y el internacional y los gobiernos provinciales regulan la producción de leche y su venta entre provincias. Los subsidios al precio de la leche fueron eliminados en 2002. Los productores de lácteos deben tener una licencia para producir y vender leche a los procesadores de lácteos. La Comisión Federal Canadiense de Lácteos se encargaba de fijar los precios de la leche y las cuotas de producción. Las provincias tienen su propio esquema de manejo de la oferta de leche fluida. El mecanismo para la carne de aves y los huevos es básicamente el mismo que para los productos lácteos.

\section{Conclusión}

En los noventa Canadá emprendió un proceso de liberalización del sector agrícola, que lo sitúa como uno de los países con menores niveles de apoyo a la agricultura entre los países miembros de la OCDE. La política agrícola de 
liberalización, además de la eliminación de las restricciones tradicionales al comercio, se complementó con una serie de programas para amortiguar el efecto que sobre el ingreso de los agricultores tendría la eliminación de subsidios.

En ese mismo período las exportaciones agroalimentarias prácticamente se duplicaron, mientras las importaciones crecían a un ritmo menor. Canadá continúa manteniendo un saldo superavitario en su balanza comercial agrícola. Al igual que México, aunque en menor proporción, Canadá tiene una gran dependencia del mercado norteamericano tanto en exportaciones como en importaciones. En el marco del TLCAN hay posibilidades para que México y Canadá amplíen su intercambio agrícola y diversifiquen sus mercados. México, por la abundancia relativa de mano obra, posee ventajas comparativas en las exportaciones de frutas y hortalizas, productos en los que Canadá depende de las importaciones en una gran proporción, para satisfacer el consumo interno. Esta constituye, por lo tanto, una veta que tiene un amplio potencial de crecimiento y que ambos países podrían aprovechar para estrechar sus lazos comerciales.

\section{Notas}

1 Cifras del Banco Mundial, World Bank Atlas 2002 y World Development Indicators 2002.

2 Canadá, Department of Foreign Affairs and International Trade, "The North American Free Trade Agreement", http://www.dfait-maeci.gc.ca.

3 Cifras de la FAO, FAOSTAT DATABASE, http://apps.fao.org.

4 Organización Mundial de Comercio (omc) "Canadá: examen de las políticas comerciales”, http:// www.wto.org, pp. 120-131.

5 Us Department of Agriculture (USDA), Economic Research Service (ERS), "Canada: Basic Information”, http:// www.ers.usda.gov

6 USDA "Canada Trade", ibidem.

7 омc, op. cit.

8 USDA, "Canada Policy", op. cit.

9 омc, op. cit. 